Validation Article

\title{
Pediatric Chest Ultrasound for Bedside Diagnosis of Pneumonia: A Validation Study for Diagnostic Options in Developing Countries
}

\author{
Christine W.S. Basanti ${ }^{1 *}$, Magd A. Kotb ${ }^{1}$, Hadeel M. Seif ${ }^{2}$, Fayez I. Farag ${ }^{3}$ and Azza K. \\ Abdelmegeid ${ }^{1}$ \\ 1 Pediatric Department, Faculty of Medicine, Cairo University, Egypt; christine.w.shaker@gmail.com, \\ magdkotb@kasralainy.edu.eg, azzakamal1718@gmail.com \\ 2 Radiology Department, Faculty of Medicine, Cairo University, Egypt; hadeel_mseif1@hotmail.com \\ 3 Pediatric Department, Al Dakhla General Hospital, Al Wadi Al Gadid, Egypt; \\ honeyfozza1983@gmail.com \\ * Correspondence: christine.w.shaker@gmail.com \\ Received: 14/8/2020; Accepted: 19/10/2020; Published online: 25/12/2020.
}

\begin{abstract}
:
Background: Pneumonia remains a major cause of morbidity and mortality in childhood with a higher burden in developing countries. Diagnosis relies on clinical findings with supporting evidence from chest X-ray (CXR) and occasionally chest computed tomography (CT).

Aim of the work: The aim of this study was to assess the role of lung ultrasonography (LUS) for bedside diagnosis of pediatric pneumonia in comparison to chest CT as a gold standard.

Methods: The study was performed on 50 children admitted to Cairo University Children's Hospitals. All children presented with the classical clinical picture of pneumonia and did CXR, LUS and chest CT.

Results: Radiological findings demonstrated lung consolidation in 48 patients (96\%) by CXR, 49 $(98 \%)$ patients by LUS and all 50 patients (100\%) by CT chest. Pleural effusion was found in 8 (16\%) patients by CT chest, all of which were detected by LUS (100\%), but only 5 were correctly detected by CXR (specificity 62.5\%) in addition to 3 false positive cases. LUS detected pleurisy in 29 children (58\%) (specificity 100\%) while X-rays did not. Also $70 \%$ of children needed sedation before CT scanning as compared to none for LUS.

Conclusion: Lung ultrasound is a sensitive, specific, safe and available tool that can be used by clinicians in cases of suspected pneumonia. It is more reliable than CXR, does not require sedation, and can be repeated at the patient's bedside with no risk of irradiation.
\end{abstract}

Level of Evidence of Study: IIB (1).

Keywords: Chest X-ray; chest CT; developing countries; lung ultrasound; community acquired pneumonia

Abbreviations: BTS: British Thoracic Society; CAP: community acquired pneumonia; CT: computed tomography; CXR: chest X-ray; IDSA: Infectious Diseases Society of America; kV: kilo Volts; LUS: lung ultrasonography; mA: milli Ampere; MHz: mega Hertz; mSv: milli Sievert; PICU: pediatric intensive care unit; SD: standard deviation; WHO: World Health Organization.

\section{Introduction}

Community acquired pneumonia (CAP) is a major cause of childhood morbidity worldwide with the highest burden in low- and middle-income countries (2) with an incidence of around 0.22 episodes per child per year, as compared to only 0.015 episodes per child per year in higherincome countries in 2010 (3). The estimate is that a child in every 5 children develops an attack of pneumonia per year in lower- and middle-income countries, while only 1 child in 66 is affected in high-income countries as reported in 2010 (4). Despite the decrease in numbers over the last two decades, pneumonia remains the principal cause of morbidity in children under five years of age and beyond the neonatal period (5). Also mortality from pneumonia despite having declined from 1.8 million in 2000 to 900,000 in 2013 is still regarded as largely preventable (6). Reducing 
pneumonia burden in terms of morbidity and mortality is a Millennium Development Goal for WHO by 2025 (7). Achieving this goal is not possible without prompt, accurate diagnosis and access to health care which, unfortunately, are still suboptimal in many countries (8). Pneumonia diagnosis is challenging, it relies upon patient symptoms, signs detected by clinical examination, various laboratory investigations as well as imaging studies. However, chest CT which is the accepted golden standard of imaging is not readily available (9). CAP is usually defined by expert boards, including The British Thoracic Society (BTS) and The Infectious Diseases Society of America (IDSA) in terms of clinical presentation; i.e. symptoms and signs (10, 11). However, implementation of the World Health Organization (WHO) guidelines (12) which relied mainly on tachypnea (a sign) in low-income countries has resulted in over-diagnosis of pneumonia among wheezy children, and under-diagnosis of asthma, with subsequent mismanagement, morbidity and mortality (13). Thus, chest radiography is vital for diagnosis of CAP and its complications (like pleural effusion or lung abscess, etc.), in the presence of tachypnea $>50 /$ min at any age, grunting, chest in-drawing, and nasal flaring (14). The advent of chest ultrasonography, was found to provide real time prompt imaging, interpretation and portability (15). In the present study we aimed to study the accuracy of lung ultrasonography in the diagnosis of pediatric CAP.

\section{Subjects and Methods}

This cross sectional study was carried out at Cairo University Children's Hospitals. The study was approved by the Pediatric Department Committee of Research and Higher Studies Research Committee of Faculty of Medicine, Cairo University in compliance to Helsinki declaration guidelines (16).

\section{Participants}

The cross-sectional study included 50 children consecutively admitted to the General Pediatric Wards and Pediatric Intensive Care Units (PICUs) of Children's Hospitals, Cairo University, Egypt. All the studied children had a confirmed diagnosis of CAP. They presented by the clinical picture of pneumonia; symptoms and signs included various combinations of: fever, cough, lethargy, chest pain and signs of respiratory distress, as tachypnea, chest retractions, grunting \pm cyanosis, inspiratory crackles and bronchial breath sounds by auscultation.

\section{Methods}

All included children were subjected to detailed history taking and clinical examination. Chest auscultation was done in 12 lung regions divided by a cephalocaudal mid-axillary line and a transversal hilar line as defined by Lichtenstein and coworkers in 2004 (17).

All children underwent the following imaging processes:

Chest X-ray

The enrolled child was placed in the supine position, and anterior portable radiographs were obtained using a Philips Mobile Medical X-ray System D 22335 (Hamburg, Germany). To obtain the best radiographic quality, time, degree of exposure and focus-film distance were adjusted for every child.

Lung parenchyma was divided into 12 regions similar to those described above (17). The extent of lung injury was defined according to the number of lung regions with radiologic signs suggestive of alveolar consolidation.

\section{Lung ultrasonography}

Lung ultrasonography was performed immediately after the chest radiography, with a Toshiba Diagnostic Ultrasound System, Toshiba Luxario 100 (Japan), and a linear 7.5 MHz probe. All lung regions were explored by lung ultrasonography. If an ultrasound abnormality was detected in a single site or several sites, then the region of interest was considered characterized by this abnormality.

Anterolateral parts of the chest wall were examined with the patient in the supine position, whereas posterior parts were examined with the patient in the lateral position. Trans-sternal, parasternal, and intercostal approaches were also adopted to image the lung, pleura, and anterior mediastinum. Ultrasound was performed by a pediatric radiologist and a general 
pediatrician who received a qualifying short-term training course at the hands of the pediatric radiologist.

CT Chest Imaging

High resolution chest CT cuts were done using GE Bright Speed 16 Detector Scanner (USA) for all patients with a low-dose, and was performed without contrast medium using $120 \mathrm{kV}, 20$ to $40 \mathrm{~mA}$, and a reconstructed layer thickness of $4 \mathrm{~mm}$ (multi-slice CT scan; effective radiation dose in the range of $0.4 \mathrm{mSv}$ ) or $120 \mathrm{kV}, 50 \mathrm{~mA}$, and a reconstructed layer thickness of $5 \mathrm{~mm}$ (one-line CT scan; effective radiation dose in the range of $1.2 \mathrm{mSv}$ ). CT scans were first analyzed by an expert in chest radiology unaware of the sonographic and radiographic results.

All scans were finally interpreted by the same pediatric radiologist.

\section{Statistical Analysis}

IBM SPSS statistics program (V. 22.0, IBM Corp., USA, 2013) was used for data analysis. Data were tabulated, and means were expressed as mean \pm standard deviation (SD). Data were tabulated as quantitative and qualitative, where parametric and non-parametric data analysis was employed respectively. Significance level was computed at 0.05 . Diagnostic validity testing, sensitivity, specificity, predictive value for positive and negative tests were employed.

\section{Results}

The mean age +/- SD of the 50 enrolled children was $2.4+/$ - 2.8 years; of them $23(46 \%)$ were males and 27 (54\%) were females. At the time of admission, the mean duration of pneumonia of the studied patients prior to hospitalization was 16.3 days \pm (SD) 9.6 days and their mean length of hospital stay thereafter was 12.18 days \pm (SD) 6.73 days. Of these patients, 20 (40\%) needed intensive care unit admission. Indications for PICU admission were the presence of impending or existing respiratory failure, shock or impaired consciousness. Tachypnea was found in all patients $(100 \%)$, cough in $96 \%$, crackles in $84 \%$, fever in $78 \%$, wheezing in $64 \%$, rhinorrhea in $46 \%$, working of accessory muscles in $42 \%$, cyanosis in $28 \%$, pleural rub in $20 \%$ and silent chest on auscultation in $10 \%$. Sedation was necessary in 35 children (70\%) during CT imaging.

Table 1: Chest findings detected by the different diagnostic imaging modalities.

\begin{tabular}{lcccc}
\hline & $\begin{array}{c}\text { Clinical } \\
\text { Examination } \\
(\mathrm{n}=50)\end{array}$ & $\begin{array}{c}\text { Chest } \\
\text { X-ray } \\
(\mathrm{n}=50)\end{array}$ & $\begin{array}{c}\text { Chest } \\
\text { Ultrasound } \\
(\mathrm{n}=50)\end{array}$ & $\begin{array}{c}\text { CT chest } \\
(\mathrm{n}=50)\end{array}$ \\
\hline Consolidation & 45 & 48 & 49 & 50 \\
\hline Pleural effusion & 6 & $5^{*}$ & $8^{*}$ & $8^{*}$ \\
\hline Pneumothorax & 1 & 1 & 0 & 1 \\
\hline Abscess & 0 & 0 & 19 & 0 \\
\hline Air Bronchogram & 0 & 7 & 29 & 21 \\
\hline Pleurisy & 10 & 0 & 31 \\
\hline
\end{tabular}

$\mathrm{P}$ value was computed using Chi square testing. Significance level was computed at 0.05. Qualitative differences between LUS and Chest X-ray were significant $(\mathrm{p}=0.0005)$. Qualitative differences between Chest X-ray and Chest CT were significant $(p=0.00002)$. Qualitative differences between LUS and Chest CT were not significant $(\mathrm{p}=0.996111) .{ }^{*}$ N.B. The 8 patients detected by LUS and CT were identical, however only 5 of them were detected by CXR and 3 were missed, while another 3 had false positive results by CXR.

Table 1 compares imaging findings as detected by CXR, LUS and CT chest. Figure 1 demonstrates some LUS images of pleural effusion, lung consolidation, air-bronchogram and pleurisy respectively, versus CXR and CT images. Both operators (the pediatric radiologist and the pediatrician) made the same sonographic diagnosis among the 50 studied children.

Tables 2 and 3 show the respective sensitivity, specificity, positive predictive value and negative predictive value of CXR versus CT chest and of LUS versus CT chest respectively. 
Radiological findings demonstrated lung consolidation in 48 patients (sensitivity 96\%) by CXR, 49 patients (sensitivity $98 \%$ ) by LUS and all 50 patients (100\%) by CT chest.

Table 2: Sensitivity and specificity of detection of radiologic findings by chest X-ray versus CT chest.

\begin{tabular}{|c|c|c|c|}
\hline & & Value (\%) & $95 \% \mathrm{CI}$ \\
\hline \multirow[t]{4}{*}{ Consolidation } & Sensitivity & 96.00 & 86.29 to 99.51 \\
\hline & Specificity & \multicolumn{2}{|c|}{ Not applicable } \\
\hline & Positive Predictive Value & 100 & 92.60 to 100 \\
\hline & Negative Predictive Value & 0.00 & 0.00 to 84.19 \\
\hline \multirow[t]{4}{*}{ Pleural Effusion } & Sensitivity & 62.50 & 24.49 to 91.48 \\
\hline & Specificity & 92.86 & 80.52 to 98.50 \\
\hline & Positive Predictive Value & 62.50 & 24.49 to 91.48 \\
\hline & Negative Predictive Value & 92.86 & 80.52 to 98.50 \\
\hline \multirow[t]{4}{*}{ Pneumothorax } & Sensitivity & 100 & 2.50 to 100 \\
\hline & Specificity & 100 & 92.75 to 100 \\
\hline & Positive Predictive Value & 100 & 2.50 to 100 \\
\hline & Negative Predictive Value & 100 & 92.75 to 100 \\
\hline \multirow[t]{4}{*}{ Air Bronchogram } & Sensitivity & 33.33 & 14.59 to 56.97 \\
\hline & Specificity & 100 & 88.06 to 100 \\
\hline & Positive Predictive Value & 100 & 59.04 to 100 \\
\hline & Negative Predictive Value & 67.44 & 51.46 to 80.92 \\
\hline \multirow[t]{4}{*}{ Pleurisy } & Sensitivity & 0.00 & 0.00 to 11.22 \\
\hline & Specificity & 100.00 & 82.35 to 100 \\
\hline & Positive Predictive Value & --- & --- \\
\hline & Negative Predictive Value & 38.00 & 24.65 to 52.83 \\
\hline
\end{tabular}

Pleural effusion was detected by CT chest in 8 patients, all of which were detected by LUS (Sensitivity: 100.00\%, specificity: 100.00 (Table 3). However, while X-ray also detected pleural effusion 8 in patients, it coincided with CT in only 5 of them while 3 others were false positive cases and three cases of effusion were missed by X-ray (Sensitivity: $62.50 \%$, specificity: 92.86\%) (Table 2).Furthermore, chest X-ray had no sensitivity in diagnosing patients with pleurisy compared to the gold standard which is CT chest while LUS had $93.55 \%$ sensitivity in diagnosing these cases (Tables 2 and 3 respectively; Figure 2).

Figure 1 demonstrates some LUS images of pleural effusion, lung consolidation, airbronchogram and pleurisy respectively, versus CXR and CT images. Both operators (the pediatric radiologist and the trained pediatrician) made the same sonographic diagnosis among the 50 studied children. Figure 2 compares results of different imaging techniques. 
I

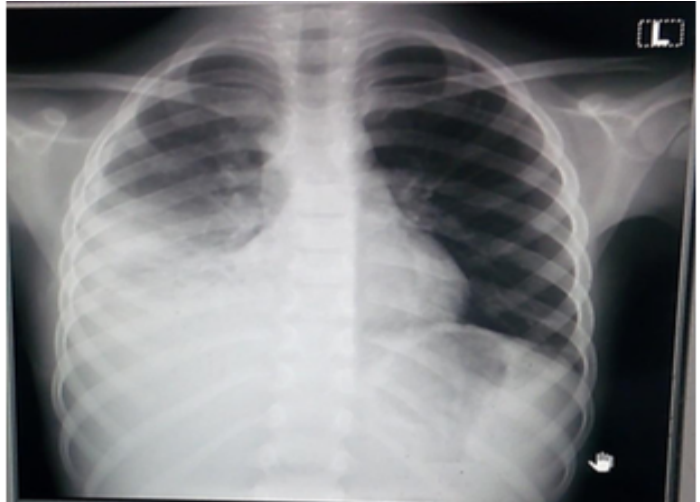

a

II

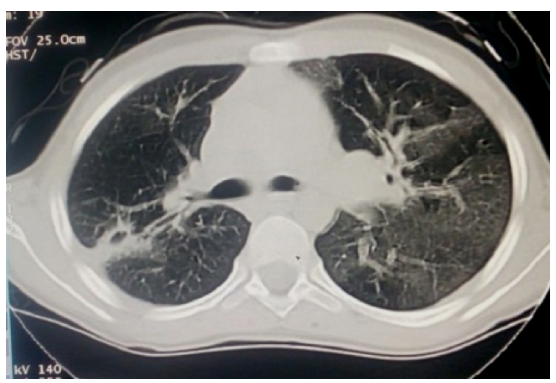

c

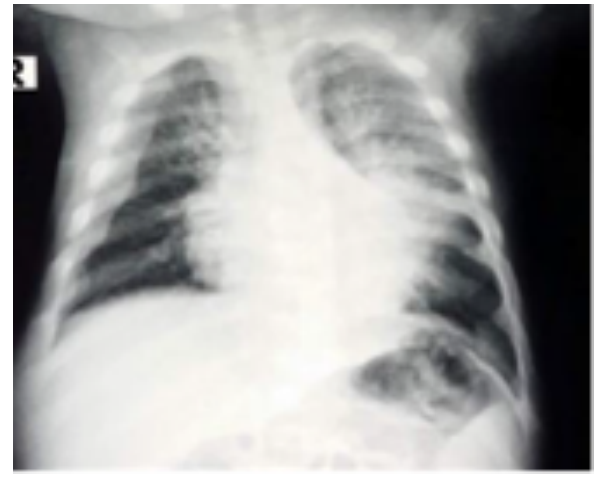

f

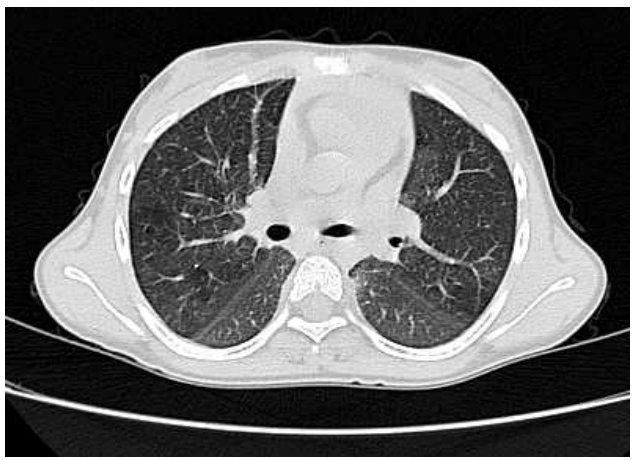

h

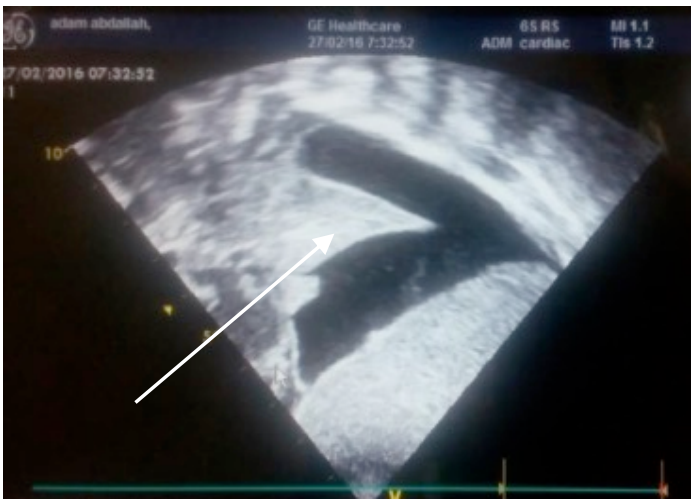

b

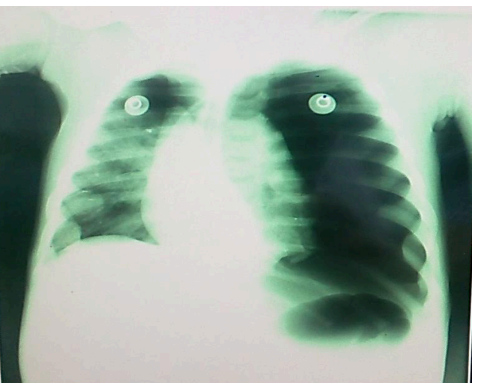

d

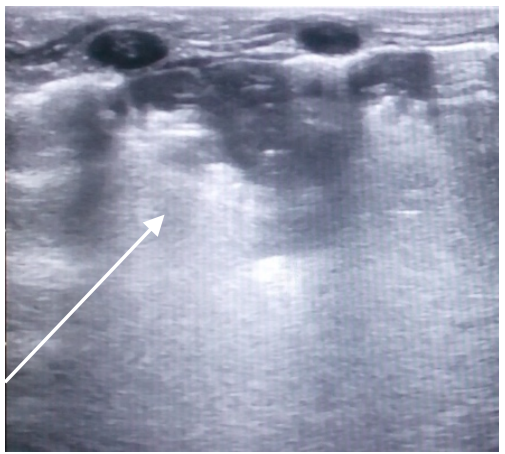

e

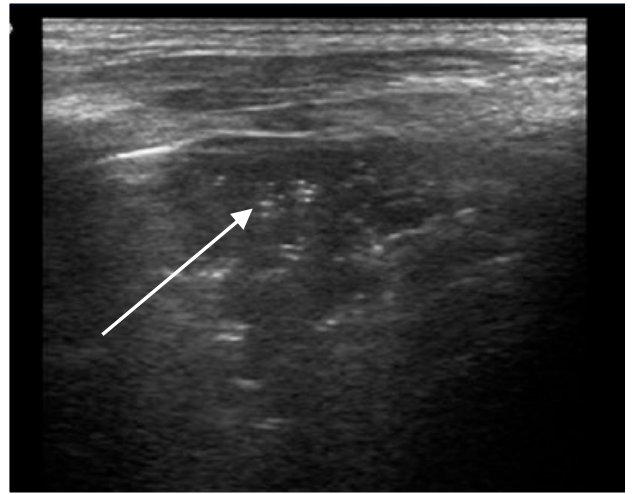

g

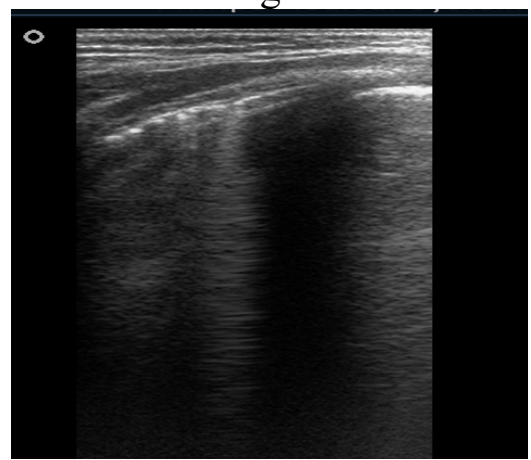

i

Figure 1. : Photographs comparing some CXR, LUS and CT images in selected cases.

I. a. CXR and b. LUS images, showing right side pleural effusion with sub-pleural areas of consolidation and sub-segmental collapse more obvious at LUS image (arrow). II. c. CT chest, d. CXR and e. LUS images, CT \& LUS detected peripheral consolidation that is not seen by X-ray, only reduced volume of right lung along with rachitic manifestations, LUS image clearly illustrates the peripherally seated sub-pleural consolidation patch (arrow head). III. f. CXR and g. LUS images, X-ray, shows marked para-hilar and left upper lobar pneumonic consolidation seen by LUS as sub-pleural patches, note the internal echogenic air bronchogram (arrow). IV. h. CT chest and i. LUS images showing pleurisy seen by US as thickened echogenic pleural line with acoustic shadowing, appearing less clear by CT study. 
Table 3: Sensitivity and specificity detection of radiologic findings by chest ultrasound versus chest CT.

\begin{tabular}{|c|c|c|c|}
\hline & & Value (\%) & $95 \% \mathrm{CI}$ \\
\hline \multirow{4}{*}{ Consolidation } & Sensitivity & 98 & 89.35 to 99.95 \\
\hline & Specificity & \multicolumn{2}{|c|}{ Not applicable } \\
\hline & Positive Predictive Value & 100 & 92.75 to 100 \\
\hline & Negative Predictive Value & 0.00 & 0.00 to 97.50 \\
\hline \multirow{4}{*}{ Pleural Effusion } & Sensitivity & 100 & 63.06 to 100 \\
\hline & Specificity & 100 & 91.59 to 100 \\
\hline & Positive Predictive Value & 100 & 63.06 to 100 \\
\hline & Negative Predictive Value & 100 & 91.59 to 100 \\
\hline \multirow{4}{*}{ Pneumothorax } & Sensitivity & 100 & 2.50 to 100 \\
\hline & Specificity & 100 & 92.75 to 100 \\
\hline & Positive Predictive Value & 100 & 2.50 to 100 \\
\hline & Negative Predictive Value & 100 & 92.75 to 100 \\
\hline \multirow{4}{*}{ Air Bronchogram } & Sensitivity & 90.48 & 69.62 to 98.83 \\
\hline & Specificity & 100.00 & 88.06 to 100 \\
\hline & Positive Predictive Value & 100.00 & 82.35 to 100 \\
\hline & Negative Predictive Value & 93.55 & 78.58 to 99.21 \\
\hline \multirow{4}{*}{ Pleurisy } & Sensitivity & 93.55 & 78.58 to 99.21 \\
\hline & Specificity & 100 & 82.35 to 100 \\
\hline & Positive Predictive Value & 100 & 88.06 to 100 \\
\hline & Negative Predictive Value & 90.48 & 69.62 to 98.83 \\
\hline
\end{tabular}

\section{Discussion}

Chest ultrasound proved to be a sensitive and specific tool in diagnosis of CAP. Our study validates other studies $(15,18-20)$, where the panoramic view provided by the transducer image allowed overseeing large areas of the peripheral and sub-pleural lung areas. In our study, CT had the highest sensitivity and specificity in diagnosis of CAP and its complications. Yet, a welltrained pediatrician operated chest ultrasound achieved a very close sensitivity and specificity, better than CXR. The false negative results by chest X-ray in diagnosis of pleural effusion could be explained by the small volume of fluid, however, such results will deny these children proper monitoring and intervention. Chest ultrasound was found to be accurate, prompt and less demanding of operator-expertise.

Chest ultrasound is a prompt diagnostic tool for diagnosis of CAP. Our studied cohort suffered from symptoms of pneumonia for an average of 16.3 days before being referred to Cairo University Children's Hospitals, and 40\% of them needed PICU admission. Generalization of pediatrician training to use chest ultrasound as a preliminary diagnostic tool might be employed for early screening of CAP to reduce its impact on morbidity and hospital admission. Further research is needed to assess the impact of such policies. Vaccination against pneumococci is still not a mandatory vaccine in Egypt's Extended Program on Immunization (21), and while vaccination has reduced the burden of CAP, it did not provide herd immunity or confer absolute reduction of morbidity and mortality $(22,23)$. Thus the prompt screening of children -with symptoms or without- using chest ultrasound might provide the needed tool to reduce community dispersion and dissemination of CAP. 


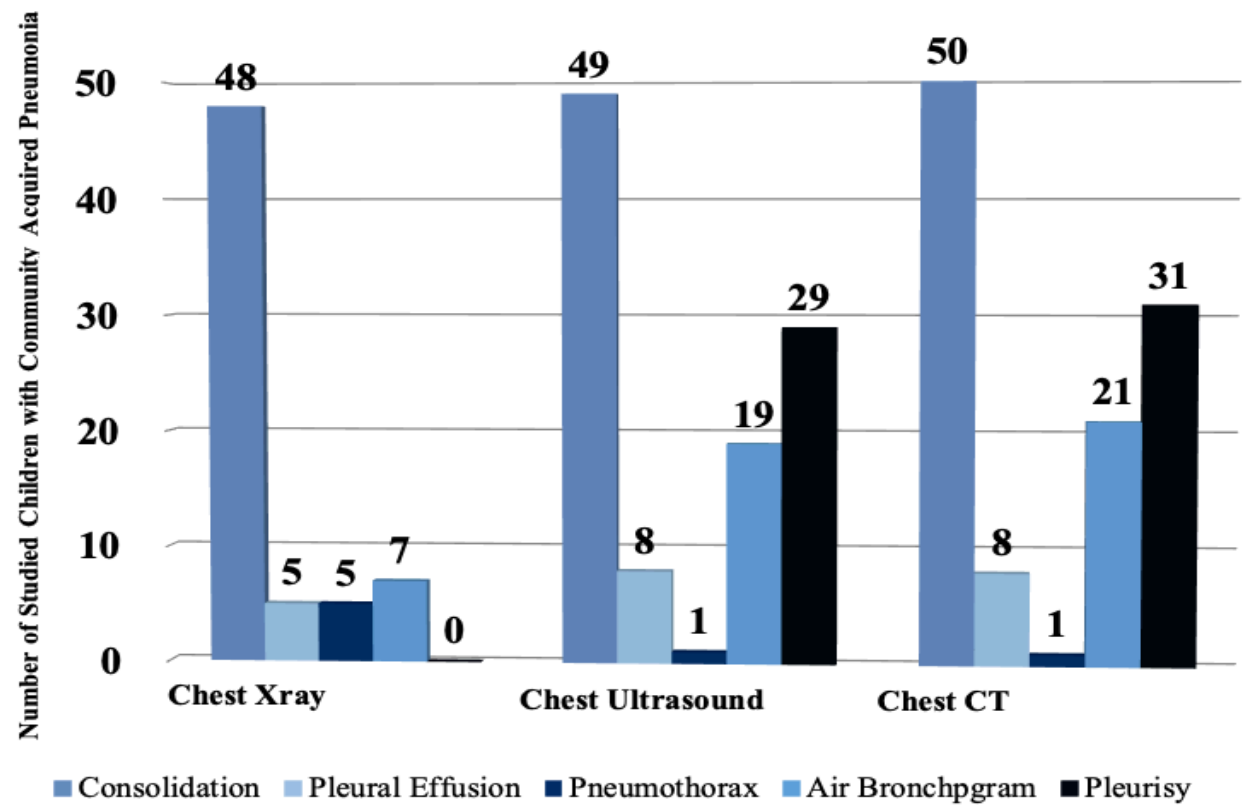

Figure 2 : Results of different imaging techniques done for studied patients with community acquired pneumonia: Chest ultrasound was found to be comparable to Chest Xray and CT.

Chest Ultrasound is safer than chest CT and chest X-ray (24). Children with complicated pneumonia especially those who undergo placement of chest tube need frequent follow up imaging, which would increase the dose of exposure to irradiation (25), whereas the ultrasound was found to be very sensitive and specific in assessment of pleural effusion. Here is room for further research to the use of chest ultrasound: to follow up the child until resolution of residual pleural effusion and removal of chest tube, as well as for follow up of consolidation in cases with prolonged/unresolving pneumonia in lieu of being exposed to doses of irradiation from repeated CXRs \&/or CTs. In this context, there is also room for research for use of LUS for diagnosis and follow up of pneumothorax. Again LUS did not require sedation or mobilizing of any of the children to another unit or facility while $70 \%$ of children needed sedation before CT scanning and all had to be moved. Hence, LUS provides a safer and more prompt diagnostic tool for CAP.

Chest ultrasound is very sensitive and specific in diagnosis of pleurisy. While pleurisy treatment is very much dependent on treatment of the cause, its detection is still vital. It might point to an underlying etiology other than CAP e.g. immune disease that involves the lung (26), or tuberculosis (27), etc. albeit being rare.

Chest ultrasound is a more available tool for the diagnosis of CAP than chest X-ray. While our study could not define the exact logarithm of indications for either X-ray or chest ultrasound, yet many settings in remote areas in Egypt have primary health care facilities for maternity and children that are equipped with portable ultrasound machines $(28,29)$, but not X-ray machines, because X-ray and CT machines require safety construction measures e.g. special lead walls, to protect against exposure to x-ray and gamma ray radiation (24). Chest ultrasound could serve as a valuable initial bed side tool for diagnosis of pneumonia that would influence reliably decision on early diagnosis, initiation of management, referral and need for intervention in a setting where other radiologic options are absent, provided the pediatrician received qualifying training at the hands of a pediatric radiologist. It is worth noting that while the linear probe is of first choice for LUS especially in neonates, the curved convex probe -that is used for maternity/abdominal US- can still provide a satisfactory image by adjusting the depth of the field of view. Thus there is no need to purchase a new probe in case the US machine in the unit lacks a linear probe.

Chest ultrasound done by the general pediatrician is efficient in diagnosis of CAP. Radiologists and clinicians can interpret cross-sectional images of CT and MRI which provide valuable imaging of the chest. Easier transfer of high quality images on mobile phones and hospital computer systems allows greater accessibility to the images and prompt diagnosis. However, these modalities are expensive, subject to availability and need patient mobility to be 
provided. Lung ultrasonography (LUS) defeats these caveats, and its training skills are easily acquired by clinicians to be performed as part of the bedside exam, not requiring specialized radiologists, mobility or excessive cost (30-33).

Last and not least, the authors are well aware that the study at hand had several limitations that should be addressed in future research. The sample size was relatively small for such a common illness with a wide array of presentations and it was carried out in a tertiary hospital setting rather than in the primary care units in the remote areas. Another limitation of the study is the lack of a control group, both for inadequate funding and to avoid exposing healthy children to irradiation from CXR and CT. Also, LUS was not used to assess CAP associated with other chest conditions, including asthma, hence, further research is needed to verify the sensitivity and specificity of LUS as a screening tool for CAP versus other chest conditions. It is also worth noting that LUS did not easily reveal consolidation in the para-hilar lung areas as it did for peripheral and sub-pleural lung regions. Moreover, our studied cohort had well established CAP of mean duration of 16.3 days. Validation research is needed to verify the role of LUS in screening and detection of early CAP and considering the generalization of training of pediatricians to use LUS as a preliminary diagnostic tool to reduce the morbidity, hospital admissions and mortality of CAP.

\section{Conclusions}

The chest ultrasound is a safe, available, portable, sensitive and specific tool for prompt diagnosis of CAP and is less demanding for interpreter expertise. The study validates earlier findings. Chest ultrasound seems very promising in screening CAP and could be part of community based screening programs to reduce the burden of CAP in developing countries.

\section{Acknowledgment}

The authors would like to acknowledge the heads, managers and workers in the Unit of Radiology, Unit of Pediatric Pulmonology, PICUs and Children's Hospitals, Faculty of Medicine, Cairo University, Cairo, Egypt for making this work possible.

\section{Author Contributions:}

C.W.S.B.: conceptualization, methodology, data analysis, writing, editing and corresponding. M.A.K.: Data analysis, writing original draft, supervising and revising. H.M.S.: Data curation and analysis, investigation and methodology, visualization and revision of writing. F.I.F.: Data curation and analysis, investigation and methodology. A.K.A.: Conceptualization, methodology, data analysis, revising and writing. All authors reviewed the final manuscript. All authors have read and agreed to the published version of the manuscript.

\section{FUNDING}

Authors declare there was no extramural funding provided for this study.

\section{CONFLICT OF INTEREST}

The authors declare no conflict of interest in connection with the reported study.

\section{References}

1. S. Tenny, M. Varacallo, Evidence Based Medicine. (StatPearls Publishing; Treasure Island (FL), 2020; https://www.ncbi.nlm.nih.gov/books/NBK470182/).

2. G. A. Tramper-Stranders, Childhood community-acquired pneumonia: A review of etiology- and antimicrobial treatment studies. Paediatr. Respir. Rev. 26, 41-48 (2018).

3. I. Rudan, K. L. O’Brien, H. Nair, L. Liu, E. Theodoratou, S. Qazi, I. Lukšić, C. L. Fischer Walker, R. E. Black, H. Campbell, Child Health Epidemiology Reference Group (CHERG), Epidemiology and etiology of childhood pneumonia in 2010: estimates of incidence, severe morbidity, mortality, underlying risk factors and causative pathogens for 192 countries. J. Glob. Health. 3, 010401 (2013).

4. H. Nair, E. A. Simões, I. Rudan, B. D. Gessner, E. Azziz-Baumgartner, J. S. F. Zhang, D. R. Feikin, G. A. Mackenzie, J. C. Moiïsi, A. Roca, H. C. Baggett, S. M. Zaman, R. J. Singleton, M. G. Lucero, A. Chandran, A. Gentile, C. Cohen, A. Krishnan, Z. A. Bhutta, A. Arguedas, A. W. Clara, A. L. Andrade, M. Ope, R. O. 
Ruvinsky, M. Hortal, J. P. McCracken, S. A. Madhi, N. Bruce, S. A. Qazi, S. S. Morris, S. El Arifeen, M. W. Weber, J. A. G. Scott, W. A. Brooks, R. F. Breiman, H. Campbell, Severe Acute Lower Respiratory Infections Working Group, Global and regional burden of hospital admissions for severe acute lower respiratory infections in young children in 2010: a systematic analysis. Lancet Lond. Engl. 381, 13801390 (2013).

5. L. Liu, S. Oza, D. Hogan, Y. Chu, J. Perin, J. Zhu, J. E. Lawn, S. Cousens, C. Mathers, R. E. Black, Global, regional, and national causes of under-5 mortality in 2000-15: an updated systematic analysis with implications for the Sustainable Development Goals. Lancet Lond. Engl. 388, 3027-3035 (2016).

6. Global Burden of Disease Pediatrics Collaboration, H. H. Kyu, C. Pinho, J. A. Wagner, J. C. Brown, A. Bertozzi-Villa, F. J. Charlson, L. E. Coffeng, L. Dandona, H. E. Erskine, A. J. Ferrari, C. Fitzmaurice, T. D. Fleming, M. H. Forouzanfar, N. Graetz, C. Guinovart, J. Haagsma, H. Higashi, N. J. Kassebaum, H. J. Larson, S. S. Lim, A. H. Mokdad, M. Moradi-Lakeh, S. V. Odell, G. A. Roth, P. T. Serina, J. D. Stanaway, A. Misganaw, H. A. Whiteford, T. M. Wolock, S. Wulf Hanson, F. Abd-Allah, S. F. Abera, L. J. AbuRaddad, F. S. AlBuhairan, A. T. Amare, C. A. T. Antonio, A. Artaman, S. L. Barker-Collo, L. H. Barrero, C. Benjet, I. M. Bensenor, Z. A. Bhutta, B. Bikbov, A. Brazinova, I. Campos-Nonato, C. A. CastañedaOrjuela, F. Catalá-López, R. Chowdhury, C. Cooper, J. A. Crump, R. Dandona, L. Degenhardt, R. P. Dellavalle, S. D. Dharmaratne, E. J. A. Faraon, V. L. Feigin, T. Fürst, J. M. Geleijnse, B. D. Gessner, K. B. Gibney, A. Goto, D. Gunnell, G. J. Hankey, R. J. Hay, J. C. Hornberger, H. D. Hosgood, G. Hu, K. H. Jacobsen, S. P. Jayaraman, P. Jeemon, J. B. Jonas, A. Karch, D. Kim, S. Kim, Y. Kokubo, B. Kuate Defo, B. Kucuk Bicer, G. A. Kumar, A. Larsson, J. L. Leasher, R. Leung, Y. Li, S. E. Lipshultz, A. D. Lopez, P. A. Lotufo, R. Lunevicius, R. A. Lyons, M. Majdan, R. Malekzadeh, T. Mashal, A. J. Mason-Jones, Y. A. Melaku, Z. A. Memish, W. Mendoza, T. R. Miller, C. N. Mock, J. Murray, S. Nolte, I.-H. Oh, B. O. Olusanya, K. F. Ortblad, E.-K. Park, A. J. Paternina Caicedo, S. B. Patten, G. C. Patton, D. M. Pereira, N. Perico, F. B. Piel, S. Polinder, S. Popova, F. Pourmalek, D. A. Quistberg, G. Remuzzi, A. Rodriguez, D. Rojas-Rueda, D. Rothenbacher, D. H. Rothstein, J. Sanabria, I. S. Santos, D. C. Schwebel, S. G. Sepanlou, A. Shaheen, R. Shiri, I. Shiue, V. Skirbekk, K. Sliwa, C. T. Sreeramareddy, D. J. Stein, T. J. Steiner, L. J. Stovner, B. L. Sykes, K. M. Tabb, A. S. Terkawi, A. J. Thomson, A. L. Thorne-Lyman, J. A. Towbin, K. N. Ukwaja, T. Vasankari, N. Venketasubramanian, V. V. Vlassov, S. E. Vollset, E. Weiderpass, R. G. Weintraub, A. Werdecker, J. D. Wilkinson, S. M. Woldeyohannes, C. D. A. Wolfe, Y. Yano, P. Yip, N. Yonemoto, S.-J. Yoon, M. Z. Younis, C. Yu, M. El Sayed Zaki, M. Naghavi, C. J. L. Murray, T. Vos, Global and National Burden of Diseases and Injuries Among Children and Adolescents Between 1990 and 2013: Findings From the Global Burden of Disease 2013 Study. JAMA Pediatr. 170, 267-287 (2016).

7. world Health Organization, End preventable deaths: Global Action Plan for Prevention and Control of Pneumonia and Diarrhoea. (World Health Organization And Unicef, 2013; https://apps.who.int/iris/bitstream/handle/10665/79200/9789241505239_eng.pdf;jsessionid=BAE5D0DF 7131A9F18A4680F34737E625?sequence=1).

8. D. A. McAllister, L. Liu, T. Shi, Y. Chu, C. Reed, J. Burrows, D. Adeloye, I. Rudan, R. E. Black, H. Campbell, H. Nair, Global, regional, and national estimates of pneumonia morbidity and mortality in children younger than 5 years between 2000 and 2015: a systematic analysis. Lancet Glob. Health. 7, e47e57 (2019).

9. C. M. C. Rodrigues, H. Groves, Community-Acquired Pneumonia in Children: the Challenges of Microbiological Diagnosis. J. Clin. Microbiol. 56 (2018), doi:10.1128/JCM.01318-17.

10. M. Harris, J. Clark, N. Coote, P. Fletcher, A. Harnden, M. McKean, A. Thomson, British Thoracic Society Standards of Care Committee, British Thoracic Society guidelines for the management of community acquired pneumonia in children: update 2011. Thorax. 66 Suppl 2, ii1-23 (2011).

11. J. S. Bradley, C. L. Byington, S. S. Shah, B. Alverson, E. R. Carter, C. Harrison, S. L. Kaplan, S. E. Mace, G. H. McCracken, M. R. Moore, S. D. St Peter, J. A. Stockwell, J. T. Swanson, The Management of Community-Acquired Pneumonia in Infants and Children Older Than 3 Months of Age: Clinical Practice Guidelines by the Pediatric Infectious Diseases Society and the Infectious Diseases Society of America. Clin. Infect. Dis. 53, e25-e76 (2011).

12. World Health Organization, Pocket book of hospital care for children Guidelines for the management of common illnesses with limited resources (World Health Organization, 2005; https://www.who.int/maternal_child_adolescent/documents/9241546700/en/).

13. M. S. Østergaard, R. Nantanda, J. K. Tumwine, R. Aabenhus, Childhood asthma in low income countries: an invisible killer? Prim. Care Respir. J. J. Gen. Pract. Airw. Group. 21, 214-219 (2012).

14. C. Rambaud-Althaus, F. Althaus, B. Genton, V. D'Acremont, Clinical features for diagnosis of pneumonia in children younger than 5 years: a systematic review and meta-analysis. Lancet Infect. Dis. 15, 439-450 (2015).

15. A. Reissig, R. Copetti, C. Kroegel, Current role of emergency ultrasound of the chest. Crit. Care Med. 39, 839-845 (2011). 
16. World Medical Association, WMA Declaration of Helsinki- Ethical Principles for Medical Research Involving Human Subjects (2013), (available at https://www.wma.net/policies-post/wma-declaration-ofhelsinki-ethical-principles-for-medical-research-involving-human-subjects/2013/).

17. D. Lichtenstein, I. Goldstein, E. Mourgeon, P. Cluzel, P. Grenier, J.-J. Rouby, Comparative diagnostic performances of auscultation, chest radiography, and lung ultrasonography in acute respiratory distress syndrome. Anesthesiology. 100, 9-15 (2004).

18. S. J. Koenig, M. Narasimhan, P. H. Mayo, Thoracic ultrasonography for the pulmonary specialist. Chest. 140, 1332-1341 (2011).

19. K. F. Alkhayat, M. H. Alam-Eldeen, Value of chest ultrasound in diagnosis of community acquired pneumonia. Egypt. J. Chest Dis. Tuberc. 63, 1047-1051 (2014).

20. D. Lichtenstein, G. Mezière, J. Seitz, The dynamic air bronchogram. A lung ultrasound sign of alveolar consolidation ruling out atelectasis. Chest. 135, 1421-1425 (2009).

21. World Health Organization Regional Office for the Eastern Mediterranean: Egypt, Expanded Program on Immunization (2019), (available at http://www.emro.who.int/egy/programmes/expanded-programme-onimmunization.html).

22. S. Chowdhary, J. Puliyel, Bull. World Health Organ., in press, doi:10.2471/blt.08.054692.

23. S. Kularatna, P. R. Wijesinghe, M. R. N. Abeysinghe, K. Karunaratne, L. Ekanayake, Burden of invasive pneumococcal disease (IPD) in Sri-Lanka: Deriving a reasonable measure for vaccine introduction decision making. Vaccine. 33, 3122-3128 (2015).

24. Radiation Health Branch Environmental Health Directorate Department of Health Western Australia, General Shielding Requirements for Diagnostic X-Ray Facilities. (2004), (available at http://www.radiologicalcouncil.wa.gov.au/PDF/FAQ/plans\%20-\%202004.pdf).

25. S. P. Knight, A paediatric X-ray exposure chart. J. Med. Radiat. Sci. 61, 191-201 (2014).

26. J. L. Medlin, K. E. Hansen, S. S. McCoy, C. M. Bartels, Pulmonary manifestations in late versus early systemic lupus erythematosus: A systematic review and meta-analysis. Semin. Arthritis Rheum. 48, 198204 (2018).

27. X. Zhou, P. Jiang, X. Huan, W. Li, Y. Chen, H. Gao, X. Qi, J. Wu, X. Wang, Y. Ou, X. Jia, UltrasoundGuided versus Thoracoscopic Pleural Biopsy for Diagnosing Tuberculous Pleurisy Following Inconclusive Thoracentesis: A Randomized, Controlled Trial. Med. Sci. Monit. Int. Med. J. Exp. Clin. Res. 24, 72387248 (2018).

28. H. C. C. C. E. 20., The Health System and Public Health. (2018), (available at http://www.mohp.gov.eg/theducation/Second-Fany-elarshad/الانظمة0\%.pdf.).

29. assciates El Zanaty, Study on Reproductive Health Impact of Family Health Model Pilots in Egypt. (2008; https://egypt.unfpa.org/sites/default/files/pub-pdf/1828cf97-c4b3-46bb-b5fa-d845a127ca8f.pdf.).

30. M. Hew, T. R. Tay, The efficacy of bedside chest ultrasound: from accuracy to outcomes. Eur. Respir. Rev. Off. J. Eur. Respir. Soc. 25, 230-246 (2016).

31. P. Joshi, A. Vasishta, M. Gupta, Ultrasound of the pediatric chest. Br. J. Radiol. 92, 20190058 (2019).

32. A. Colli, D. Prati, M. Fraquelli, S. Segato, P. P. Vescovi, F. Colombo, C. Balduini, S. Della Valle, G. Casazza, The use of a pocket-sized ultrasound device improves physical examination: results of an in- and outpatient cohort study. PloS One. 10, e0122181 (2015).

33. E. J. Denton, L. M. Hannan, M. Hew, Physician-performed chest ultrasound: progress and future directions. Intern. Med. J. 47, 306-311 (2017). 